\title{
Evaluation of error types and quality on panoramic radiography
}

\author{
Ceren Aktuna Belgin ${ }^{1} \oplus$, Gözde Serindere ${ }^{1}(\mathbb{D}$ \\ ${ }^{1}$ Hatay Mustafa Kemal University, Faculty of Dentistry, Department of Dentomaxillofacial Radiology, Hatay, Turkey.
}

\section{Correspondence:}

\section{Dr. Ceren AKTUNA BELGIN}

Hatay Mustafa Kemal University, Faculty of Dentistry, Department of Dentomaxillofacial Radiology, Hatay, Turkey.

E-mail:dtcaktuna@gmail.com

Received: 6 May 2019

Accepted: 5 August 2019

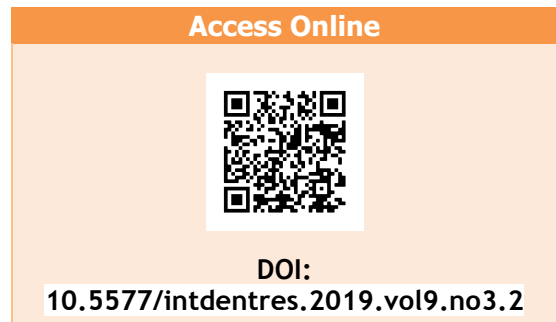

\section{Introduction}

Since its introduction by Numeta and Patero in the early 1960s, the panoramic radiograph has been an extra-oral method commonly used in dentistry as a diagnostic tool $(1,2)$. In order to obtain panoramic radiographic images in accordance with the

\begin{abstract}
Aim: The aim of this study was to investigate the prevalence of panoramic radiographic errors and to evaluate the correlation between age and panoramic radiographic error types.

Methodology: A total of 500 panoramic radiographs (259 male, 241 female) which had been taken for various reasons were randomly selected from the archive of our dentomaxillofacial radiology department. Patients were divided into six age groups and by sex. The assessed errors included the tongue not in contact with the palate, slumped position, patients not biting on bite block, patient movement, the chin tipped high, the chin tipped low, the patient positioned forward, the patient positioned backward, patient's head turned to one side, foreign bodies in the image, exposure errors, positioning error of the lips and missing image. The quality of each radiograph was rated as excellent, diagnostically acceptable or unacceptable.

Results: One or more errors were detected in $317(63.4 \%)$ of the 500 panoramic radiographs, while no error was found in $183(36.6 \%)$ of the images. It was observed that the most common error type was the slumped position (13.2\%). All of the panoramic radiographs were evaluated according to the quality criteria: only $15 \%$ of the images were classified as "excellent", 48.2\% were rated "inadequate for diagnosis" and $36.8 \%$ were graded "adequate for diagnosis". It was recorded that "slumped position" and "patient movement" errors were statistically significant in $>56$ years $(p<0.05)$.

Conclusions: Patients can be protected from unnecessary radiation exposure by investigating the causes of panoramic radiographic errors and by providing appropriate training to technicians.
\end{abstract}

Keywords: Panoramic radiography, error type, error quality

How to cite this article: Aktuna Belgin C, Serindere G. Evaluation of error types and quality on panoramic radiography. Int Dent Res 2019;9(3):99-104. appropriate standards, patients should be positioned in the so-called "ski position". In this position, the patient holds his shoulders and neck upright by joining his feet forward and stretching his back slightly. In addition, the head should be positioned according to the Frankfort horizontal plane, the jaw should be placed in the focal trough and the tongue should be moved to the palate, where it should remain motionless (3). 
The requirements for a high-quality panoramic radiograph are: fine detail in the image, minimal distortion, absence of artifacts and contrast sufficient for diagnostic purposes (4). To obtain panoramic radiographs adequate for diagnosis, it is necessary to prepare the patients appropriately with their jaws positioned in the focal trough (5). For an accurate diagnosis, it is important to obtain radiographs of sufficient quality from a diagnostically.

Inadequate diagnostic quality radiographs both lose diagnostic significance and cause unnecessary radiation to patients because they need to be repeated (6). Low-quality images are not the result of technical limitations, but are caused by errors made by the operator during the positioning of the patient, during irradiation or during film processing when conventional radiographic techniques are used (7).

The first aim of our study was to highlight the basic criteria by which should be known in order to recognize the radiographs taken by an inappropriate technique without preparing the necessary preconditions by emphasizing the frequency of errors in panoramic radiographs, and secondly, we sought to evaluate the correlation between age and panoramic radiography error types.

\section{Materials and Methods}

The design of this retrospective study was approved by the Local Ethics Committee of Hatay Mustafa Kemal University, and the study protocol was conducted in accordance with the principles set out in the Declaration of Helsinki.

A total of 500 panoramic radiographs (259 male, 241 female) which had been taken for various reasons (dental caries, gum diseases, temporomandibular joint problems, orthodontic treatment needs, etc.) were randomly selected from the archive of the Department of Dentomaxillofacial Radiology at Hatay Mustafa Kemal University during the period December 2018 February 2019. Radiographs of children less than 13 years of age were excluded from the study. Patients were divided into six age groups (13-18 years [ $n=48]$, 19-24 years $[n=80$ ], 25-35 years [ $n=136$ ], 36-45 years $[n=102], 46-55$ years $[n=73]$, and $\geq 56$ years $[n=61]$ ) and by sex.

All images were taken with the Digital Panoramic device (Planmeca, Helsinki, Finland) with settings of 70 $\mathrm{kVp}$ and $10 \mathrm{~mA}$. The radiographs were evaluated under identical conditions without any modifications on a 15 inch, $1280 \times 800$ resolution, 32 -bit color mode computer monitor (Dell Inc, Round Rock, TX, USA), in a room with subdued lighting. All images were analyzed by two dentomaxillofacial radiologists and the results were recorded.

Assessed errors included the tongue not in contact with the palate, slumped position, patients not biting on the bite block, patient movement, the chin tipped high, the chin tipped low, the patient positioned forward, the patient positioned backward, the patient's head turned to one side, foreign bodies in the image, exposure errors, positioning error of the lips and missing image $(8,9)$ (Figure 1-5).

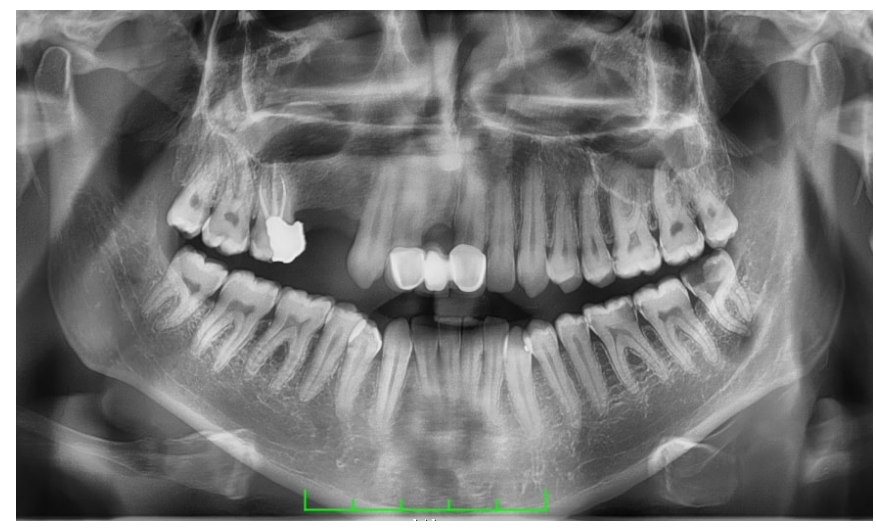

Figure 1. The chin positioned below.

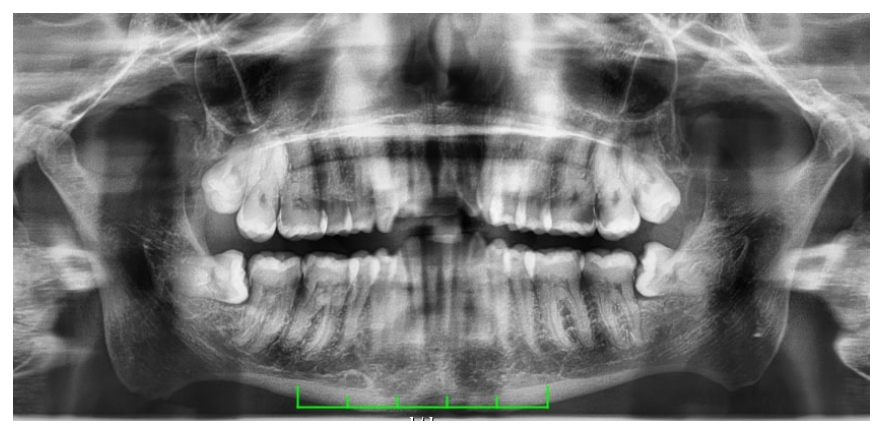

Figure 2.Patient positioned forward from focal trough

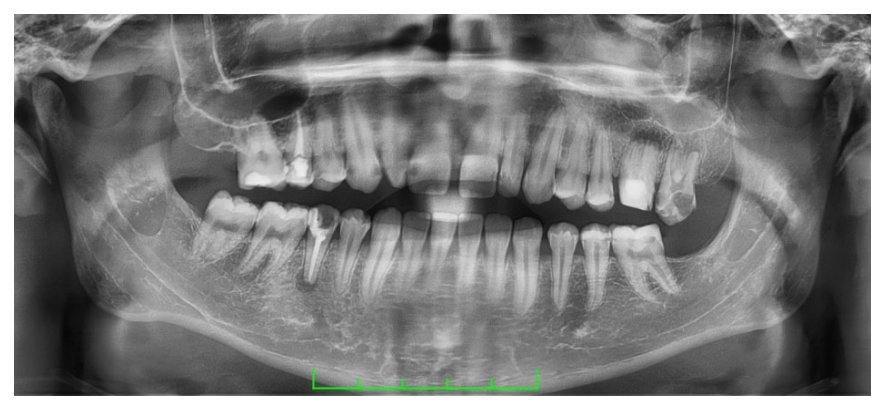

Figure 3. Positioning error of the lips and and the patient's positioned backward

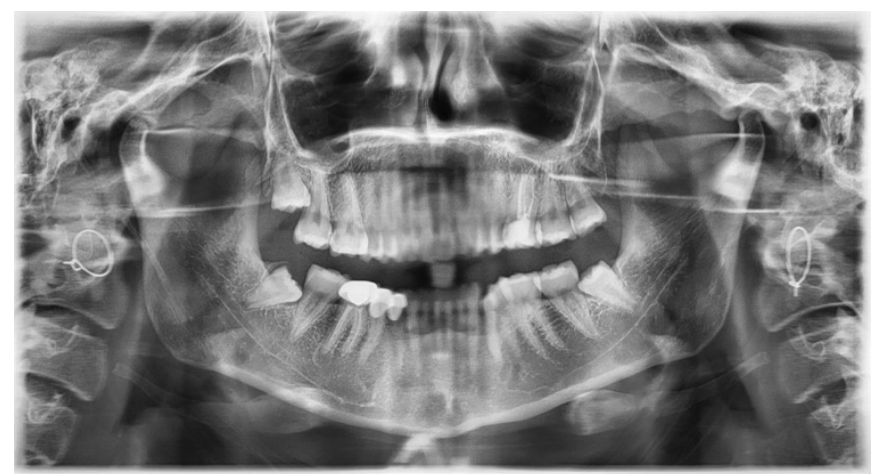

Figure 4. Foreign bodies are caused radiopaque image and ghost image. 


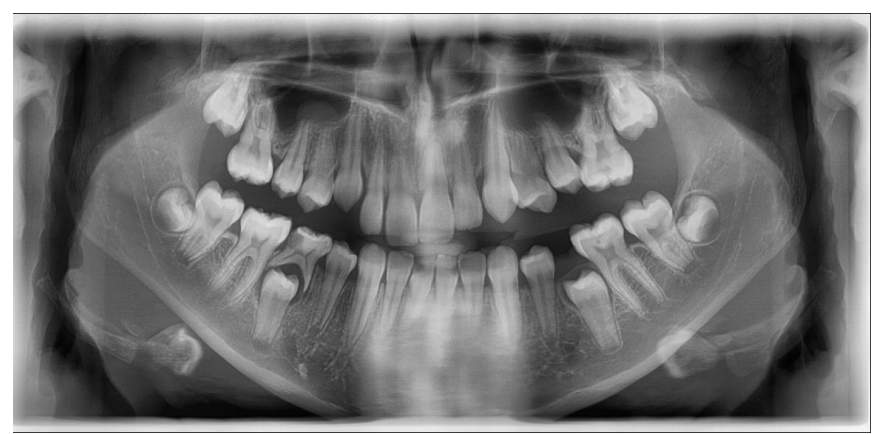

Figure 5. Missing image, TMJ are not in the panoramic image.

Descriptions of the error categories are shown in Table 1. Finally, each radiograph was quality rated as per National Radiological Protection Board guidelines as excellent, diagnostically acceptable or unacceptable (3) (Table 2).

\section{Statistical Analysis}

Interobserver agreement was detected using a calibration analysis against a set of 50 reference images and intraclass correlation coefficient (ICC). ICC values ranged from 0.00 to 1.00 . An ICC value between 0.60 and 0.80 indicated "good", while $0.80-1$ indicated "excellent" compatibility. The correlations between error type and age were calculated by conducting a chisquare test of independence. $P$ values $<0.05$ were considered to indicate statistical significance. Statistical analyses were carried out using the SPSS 21.0 software (SPSS, Chicago, IL, USA).

\section{Results}

Interobserver correlation calculations determined that each measuring point (ICC: 0,894) was "excellent". One or more errors were detected in 408 (81.6\%) of the 500 panoramic radiographs, while no errors were found in $92(18.4 \%)$. The most common error type was the slumped position (13.2\%), followed by "the tongue not in contact with palate" (10.6\%), "exposure error" (10.0\%) and "ghost image" (10.0\%) (Fig. 1). When the quality of the panoramic radiographs was evaluated according to the criteria, only $18.4 \%$ of the images were classified as "excellent", $31.3 \%$ were "inadequate for diagnosis" and $50.3 \%$ were rated "adequate for diagnosis".

As the age of the patients increased, the rate of error in the panoramic images increased significantly ( $p$ $<0,05)$; however, it was observed that gender errors did not significantly correlate with panoramic radiograph errors ( $p>0.05)$. Correlation of error types by age is shown in Table 3. It was recorded that the "slumped position" and "patient movement" errors were statistically significant in $>56$ years $(p<0.05)$. Errors involving "foreign bodies" were statistically significant among those aged 19-24 years and $>56$ years, while it was found that the "patient positioned forward" error was statistically higher among those aged 19-24 years and $36-45$ years $(p<0.05)$. The "exposure" error was statistically higher in those aged $>36$ years $(p<0.05)$.

Table 1. Description of the error categories.

\begin{tabular}{|c|c|c|}
\hline $\begin{array}{l}\text { Error Type } \\
\text { Number }\end{array}$ & Error type & Description of the Radiographic Obtained Image \\
\hline Type 1 & The tongue not contact with palate & $\begin{array}{l}\text { Radiolucent area in the apex of the maxillary teeth } \\
\text { due to palatoglossal airspace. }\end{array}$ \\
\hline Type 2 & Slumped position & $\begin{array}{l}\text { Radiopaque area in the anterior teeth due to } \\
\text { superposition of the spina. }\end{array}$ \\
\hline Type 3 & Patients not biting on bite block & Overlap the lower and upper teeth. \\
\hline Type 4 & Patient movement & All or some structures on the image are blurred. \\
\hline Type 5 & Foreign bodies & $\begin{array}{l}\text { Jewellery, glasses, oral appliances are caused } \\
\text { radiopaque image in the panoramic radiography and } \\
\text { contralaterally magnified ghost image. }\end{array}$ \\
\hline Type 6 & Patient positioned forward & $\begin{array}{l}\text { Anterior teeth in both arches are blurred and narrow. } \\
\text { Also the spine superimposed over anterior region. }\end{array}$ \\
\hline Type 7 & Patient positioned backward & $\begin{array}{l}\text { Anterior teeth in both arches are blurred and wide. } \\
\text { Also excessive ghosting of mandible and spine. }\end{array}$ \\
\hline Type 8 & Patient's head turned to right side & $\begin{array}{l}\text { The teeth which are the right side and the right } \\
\text { mandibular ramus are narrower and shorter. Also the } \\
\text { nasal structures are not clear. }\end{array}$ \\
\hline Type 9 & Patient's head turned to left side & $\begin{array}{l}\text { The teeth which are the left side and the left } \\
\text { mandibular ramus are narrower and shorter. Also the } \\
\text { nasal structures are not clear. }\end{array}$ \\
\hline Type 10 & The chin tipped low & $\begin{array}{l}\text { Blurring of lower root apices, shadow of hyoid } \\
\text { bone on anterior mandible, mandible shaped like a } \\
\text { "V", too much smile line. }\end{array}$ \\
\hline
\end{tabular}




\begin{tabular}{|c|c|c|}
\hline Type 11 & The chin tipped high & $\begin{array}{l}\text { Blurring of upper incisors, hard palate superimposed } \\
\text { on roots, flat occlusal plane, mandible is broad and } \\
\text { flat, and condyles at edge of film. }\end{array}$ \\
\hline Type 12 & Exposure errors & Under or over exposed. \\
\hline Type 13 & Positioning error of the lips & $\begin{array}{l}\text { Open lips are caused radiolucent area in the coronal } \\
\text { part of the anterior teeth. }\end{array}$ \\
\hline Type 14 & Missing image & $\begin{array}{l}\text { TMJ, maxillary sinuses or mandible corpus are not in } \\
\text { the panoramic image. }\end{array}$ \\
\hline
\end{tabular}

Table 2. Criteria for excellent, adequate or inadequate image quality

\section{Excellent:}

\section{There were no errors of positioning}

Adequate for diagnosis:

Quality image providing sufficient information, with one error from image taking procedure that does not affect the diagnosis.

Inadequate for diagnosis:

Poor quality image, with 2 or more errors that cannot be accepted in diagnostically and required repetition

Table 3. Comparison of the age groups and error type

\section{Age (Years)}

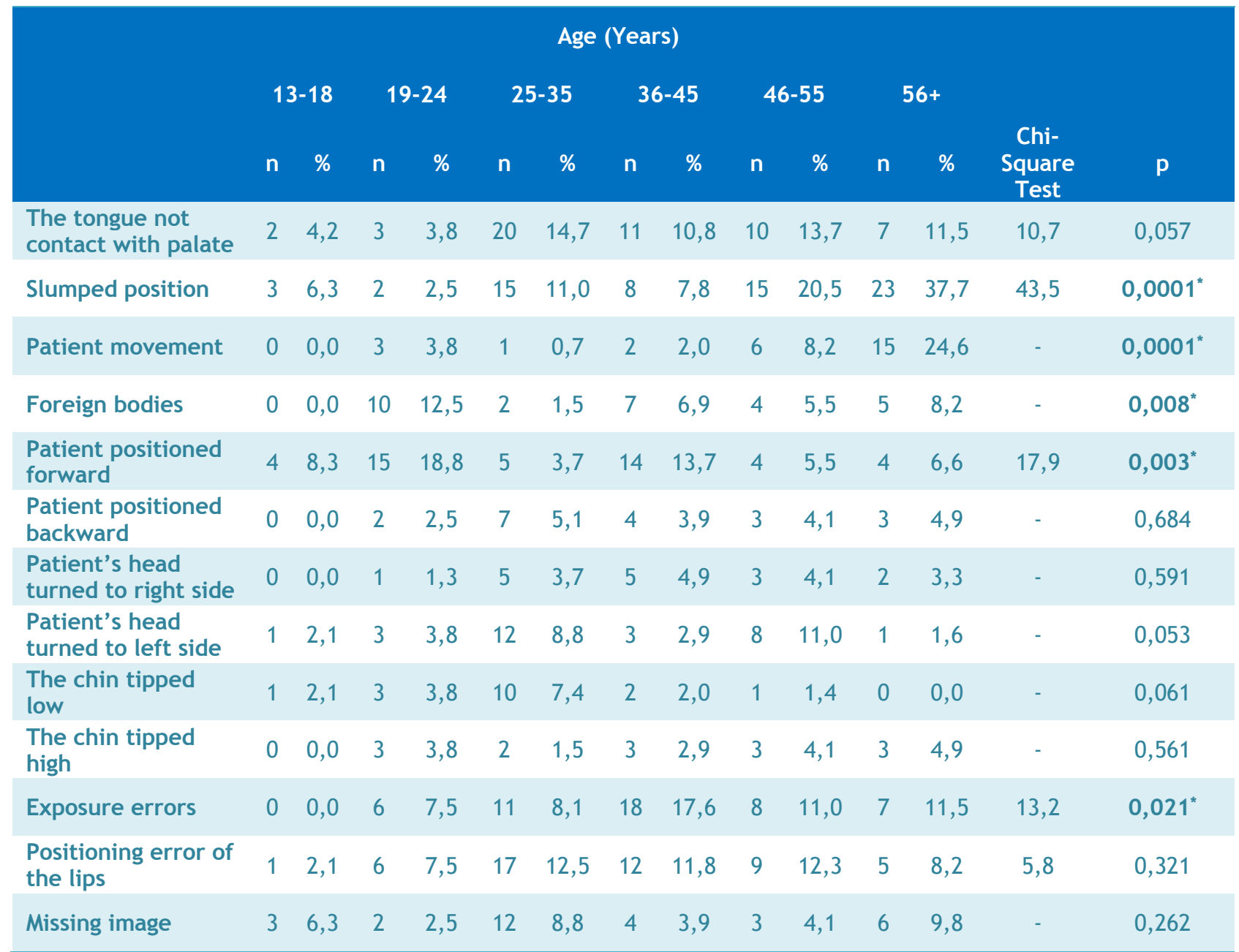

*Significant differences are indicated in bold 


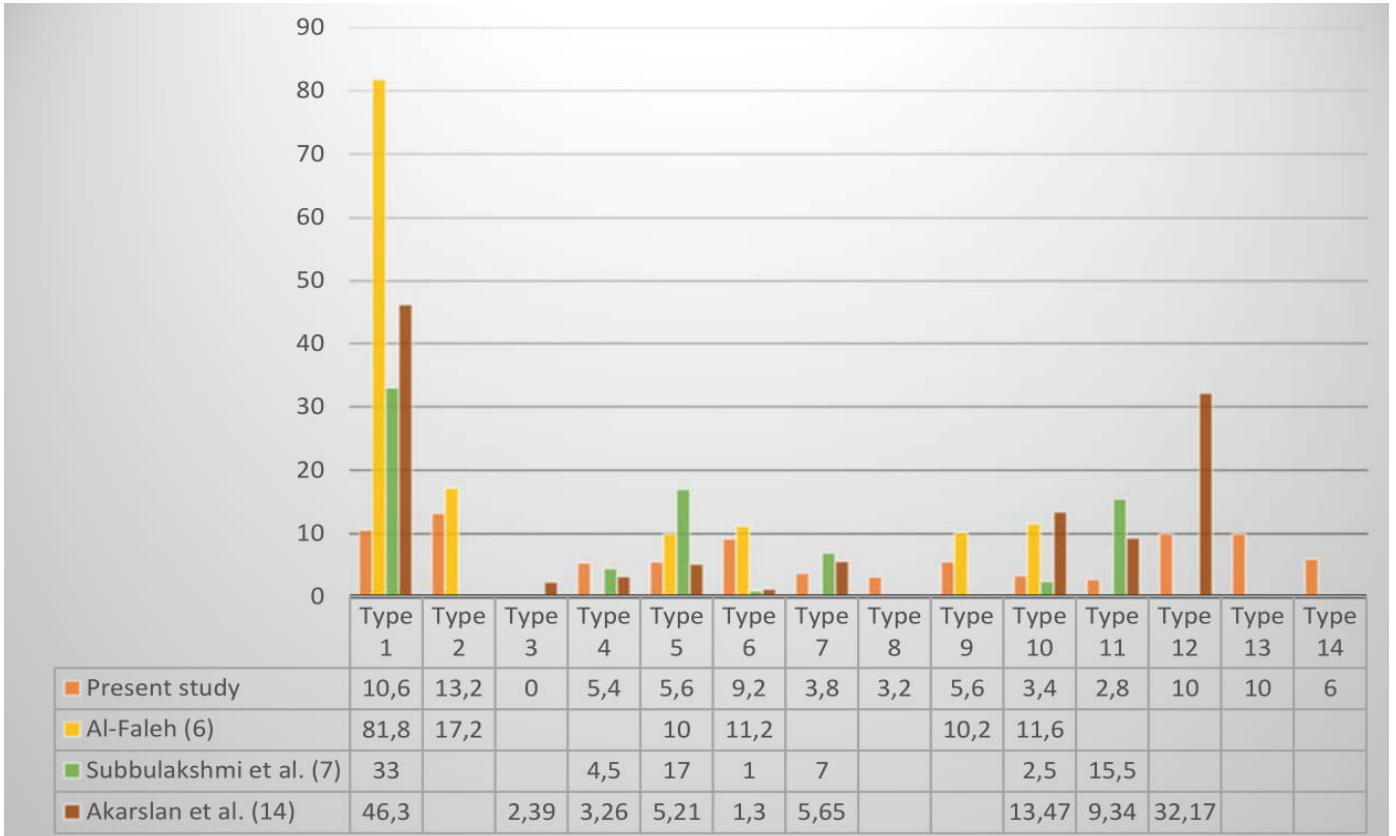

Graphic 1. Comparison the prevalance of panoramic image error types between the literature and the present study (\%)

\section{Discussion}

Panoramic radiographs are an extra-oral imaging method that allow us to see the lower $1 / 3$ of the maxillary sinus, both TMJ structures, and dentoalveolar structures on a single radiograph. Panoramic radiographs usually show magnification of between $10 \%$ and $30 \%$. Therefore, errors in the positioning of the patients cause this magnification to become even more disproportionate. This problem may cause errors in measurements on panoramic images and incorrect diagnosis (10). Therefore, patient positioning is very important. In the correct positioning, the patient's head should be positioned on the Frankfort horizontal plane, the canin-meatus line and the midsagittal line. If this regulation is not observed, the patient can tilt his head to the right, left, front or back. When the patient's head is tilted to one side, the teeth near the $\mathrm{X}$-ray will appear to be wider and longer on the image. On the other hand, when the patient bows his head forward or backward, the occlusal plane increases curvature or flattening, and the roots of the anterior teeth are blurred. The patient's head must be fixed to prevent patient movement. The technician must inform the patient of the "ski position" in order to prevent superposition of the spina in the anterior region. In panoramic radiographs, the focal trough is the area where the curvature dental arch image is viewed at its clearest and highest quality. Therefore, the patient's jaw should be in the focal trough. The patient must bite the bite bar to avoid overlap with the teeth. Touching the tongue on the palate should also prevent the formation of radiolucent areas on the roots of the maxillary anterior teeth $(5,11)$.

In other studies, Ruston et al. (12) found that $33 \%$ of their radiographs were unacceptable for diagnosis, Dhilion et al. (8) found that $24.9 \%$ were unacceptable and Brezden and Brooks (13) found that
$18.2 \%$ of their radiographs were inadequate for diagnosis. In our study, this rate was $31.3 \%$. Errors in panoramic radiographs may obscure an existing pathology. For example, when the tongue is not touched to the palate, the radiolucent area may camouflage a cyst in the maxillary anterior. On the other hand, ghost images formed by foreign bodies may cause a diagnosis as superposed on odontoma, fracture line, maxillary sinus pathologies, etc. Patient movement or incorrect positioning of the patient may lead to misdiagnosis. The overlaps in the anterior teeth caused by not biting on the bite block can lead to the misdiagnosis of mesiodens in this area. Therefore, it is very important to improve the quality of the images by minimizing errors in panoramic radiographs.

Subbulakshmi et al. (7) found that $64 \%$ of radiographs showed one or more positioning errors and also reported that the most common error type was the tongue not in contact with the palate $(33 \%)$. A study reported by Al-Faleh (6) reported a $93.6 \%$ error rate in panoramic images. Similar to Subbulakshmi et al (7), Al-Falef (6) stated that the most common error type was palatoglossal air-space on the apex of the maxillary incisors. In this study, despite the fact that we were working with more images, the rate of faulty images was reported to be $63.4 \%$, which is similar to the results obtained by Subbulakshmi et al (7). In contrast to both studies, the most common type of error was "slumped position". Akarslan et al. (14) stated that the rate of asymmetrical placement of teeth caused by a patient's head rotation to one side was $11.52 \%$. In contrast to this study, we evaluated this error type by dividing it into two groups: right rotation and left rotation. Similar to the work of Akarslan et al (14), our study calculated this error at $8.8 \%$. A comparison of the prevalence of panoramic image error types between the literature and the present study is shown in Graphic 1. 
To our knowledge, no studies evaluate the correlation between panoramic radiograph error types and age. Our study found that "patient movement" and "slumped position" errors were more frequent in patients older than 56 years. It is thought that these errors are frequently experienced due to the difficulties of positioning older patients, especially those Parkinson's patients who have difficulty staying still. Our study observed that foreign body artifacts were correlated with age. The use of age-specific aids (e.g. piercing in the 19-24 age group, metallic partial dentures in the 56 years age group, glasses, etc.) was found to constitute a statistically significant foreign body artifact in the images. Contrast errors due to exposure dose were more significant in the $>36$ age group. These errors may be caused by the effects of aging, especially changes in the density, thickness, etc., of soft and hard tissues.

\section{Conclusions}

Patients can be protected from unnecessary radiation by investigating the types of errors that can be seen more frequently in certain age groups. In order not to miss the pathologies that are revealed in panoramic radiographs, and to prevent misdiagnoses, it is necessary to know the causes of the errors and to provide suitable training to technicians.

Ethical Approval: Ethics committee approval was received for this study from Hatay Mustafa Kemal University.

Peer-review: Externally peer-reviewed.

Author Contributions: Conception- C.A.B.; Design- C.A.B., G.S.; Supervision- C.A.B., G.S.; Materials-C.A.B.,G.S.; Data Collection and/or Processing-C.A.B., G.S.; Analysis and/or Interpretation- G.S., C.A.B., Literature Review-C.A.B., Writer-C.A.B., Critical ReviewG.S.

Conflict of Interest: No conflict of interest was declared by the authors.

Financial Disclosure: The authors declared that this study has received no financial support.

\section{References}

1. Whaites E. The Quality of Radiographic Images and Quality Assurance: Principles of Radiographic Interpretation. 3rd ed. Longman Group UK Limited: Elsevier; 2002. p. 179-93.

2. Hart D, Wall BF, Hiller MC, Shrimpton PC. Frequency and collective dose for medical and dental X-ray examinations in the UK, 2008. Health Protection Agency, 2010.

3. Hirschmann PN. Guidelines on radiology standards for primary dental care: a resumé. Royal College of Radiologists and the National Radiological Protection Board. Br Dent J 1995; 178(5):165-7. (Crossref)

4. Ezoddini Ardakani F, Zangouie Booshehri M, Behniafar B. Evaluation of the distortion rate of panoramic and periapical radiographs in erupted third molar inclination. Iran J Radiol. 2011;8(1):15-21.

5. White SC, Pharaoh MJ. Oral Radiology: principles and interpretation. 7th ed. St. Louis - Missouri: Elsevier Mosby; 2014. p.166-77.

6. Al-Faleh W. Common positioning errors in panoramic radiography. Egyptian Dent J 2005;51:1813-17.

7. Subbulakshmi AC, Mohan N, Thiruneervannan R, Naveen S, Gokulraj S. Positioning errors in digital panoramic radiographs: A study. J Orofac Sci 2016;8:22-6. (Crossref)

8. Dhillon M, Raju SM, Verma S, et al. Positioning errors and quality assessment in panoramic radiography. Imaging Sci Dent 2012;42(4):207-12. (Crossref)

9. Choi BR, Choi DH, Huh $\mathrm{KH}$, et al. Clinical image quality evaluation for panoramic radiography in Korean dental clinics. Imaging Sci Dent 2012;42(3):183-90. (Crossref)

10. Colak M, Adiguzel O, Aktuna Belgin C, Falakaloglu S, Akkus Z. Reliability of linear distance measurements of surgical implants and gutta percha lengths used in endodontic treatment with standardized digital radiography. Int Dent Res 2017;7:1-5. (Crossref)

11. Närhi TO, Leinonen K, Wolf J, Ainamo A. Longitudinal radiological study of the oral health parameters in an elderly Finnish population. Acta Odontol Scand 2000;58(3):119-24. (Crossref)

12. Rushton VE, Horner K. The use of panoramic radiology in dental practice. J Dent 1996;24(3):185-201. (Crossref)

13. Brezden NA, Brooks SL. Evaluation of panoramic dental radiographs taken in private practice. Oral Surg Oral Med Oral Pathol 1987;63:617-21. (Crossref)

14. Akarslan ZZ, Erten H, Güngör K, Celik I. Common Errors on Panoramic Radiographs Taken in a Dental School. J Contemp Dent Pract 2003;(4)2:24-34. (Crossref) 